\title{
Establishment of Baseline using Electronic Distance Measurement
}

\author{
D. M. Zakari ${ }^{1}$, A. Aliyu ${ }^{2}$ \\ ${ }^{I}$ Department of Surveying \& Geo-Informatics Adamawa State Polytechnic Yola,Adamawa State \\ ${ }^{2}$ Department of Surveying \& Geo-Informatics Modibbo Adama University of Technology Yola, Adamawa State
}

\begin{abstract}
This research aimed at establishing a baseline using Electromagnetic Distance Measuring Instrument (EDM). Considering the high accuracy of EDM instrument, this will therefore focus on the establishment of baseline in the chosen area (Federal Polytechnic Mubi) to take care of some survey operations that may require the need for a baseline. (Calibrating instruments and establishing first and second order controls). Furthermore, the development of computer programme (FORTRAN 77 language) based on least squares adjustment by observation equation method could provide an efficient method and solution to other problems relating to baseline determination.
\end{abstract}

Key Words: Baseline, EDM, Calibration

\section{Introduction}

Baseline measurement is an important aspect in the surveying operations such as traversing, triangulation, trilateration, setting out etc. The measurement of baseline was in the past century carried out by instruments such as tapes, chains bands before the advent of Electromagnetic Distance Measuring Instrument $(E D M)$. Distance measurements by electromagnetic means have virtually replaced the method of measuring baseline using the early instruments. The advent of EDM equipment has completely revolutionaries all surveying procedures and resulted in a change of emphasis and techniques, by reason of the fact that distance can now be measured quickly and accurately, regardless of terrain condition [12]. Positions can be determined by measurements made on baseline. This can be achieved by measuring all the angles in the network and by measuring the length of one or more baselines. Starting at a baseline, application of the sine rule in each triangle throughout the network enables the length of all angle sides to be calculated. These lengths combined with the measured angles enable the coordinates of stations to be computed, [6].

Baselines can also be computed from coordinates. For instance main side control points, such as traverse station can be used to establish base line from which setting out can be carried out. Subsidiary lines can be set off from the base lines to established design and corner point. The baseline may be specified by a designer and include in the contract between promoter and contractor. Baseline can take many forms; they can run between existing buildings making the boundary of an existing development, be the direction of a proposed pipeline or the center line of new road. The accuracy of base line measurement is increased if two base lines at right angle to each other are used on site. Design points can be established by offsetting from both lines and a grid system can be set up to provide additional control points in the area enclosed by the base line. Base lines can be used to form grids which consequently provide reference grid on site, [10].

The introduction of Electro-optical Microwave EDM Equipment in the early 1950s has observed a marked increase in distance measurement. The use of that EDM equipment eliminates the need for elaborate baseline preparation. Utilization of EDM vastly simplifies the measurement of baseline [6]. Since 1950, measurement of baseline by invar wires has been substituted by a much more convenient system of measurement that is the use Electro Magnetic Distance Measurement (EDM) [5]. The use of EDM eliminates the need for elaborate baselines preparations. The time required to make the necessary instrument reading during the actual measuring operation is independent of the length of the baseline, [6].Several Authors have written on different aspects of baseline, for instance [1] noted that, to locate a building either two or more baselines or a fixed point are necessary. They further stated that in setting out houses, the base may be the building line as define by the local authority or the road line. On an industrial estate the base line may be the grid lines. It is also necessary to have a site plan with a baseline drawn on it together with the ground plan of the proposed buildings.

[17] Reported that, until about 1960, the scale of triangulation networks constructed from angle measurements was derived from baseline having length of 5 to $10 \mathrm{~km}$. A Geomatic Satellar triangulation between 1966 and 1970 was carried with a BC4 Camera mounted on balloon Satellite Pageos. The scale of the network was obtained from seven baselines which were measured in polygon traverse with geodimeter and tallorometer. High - precision terrestrial-and GPS-geodetic survey were conducted in 1997 to provide the 
control coordinates of the monuments through a collaborative venture among the Geodesy Group. Importantly, part of the facility is connected geodetically to an existing EDM calibration baseline.

This EDM baseline comprises part of the national standard for length [7]. The EDM pillars and GPS pillars are regularly re-observed using an EDM that has a current regulation 80 certification from the measurement laboratory. Considering the importance of base line to some surveying operations, much work have also been done on the measures to be taken in other to achieve the best result in the establishment of the baseline. [5], noted that the invar tapes commonly used for baseline measurement have a coefficient of expansion of one eight (1/8) to one tenth (1/10) and therefore the length of the tape should be precisely determined by comparing with a standardized length. [4, 12].[16] stated that once a baseline has been established, the instrument should be calibrated by measuring the baseline at periodic intervals to guard against frequent drift. In order to achieve maximum accuracy in base line establishment, [12] observed that in given electro-optical system, cyclic error must also be evaluated. They also noted that it is necessary to set up a calibration base, for the calibration of the EDM. Base on the available literature, it is clear that much work has been done on the establishment of baseline in different places. This project will therefore focus on the establishment of baseline in the chosen area to take care of some survey operations that may require the need for a baseline.

The objectives of this study are as follows:

* To set out a baseline and measure the length thirty times using EDM.

* To reduce the measurements to correction of meteorological effect and apply the slope correction.

* To use a least squares method to find the most probable value from the set of measurements.

* To develop a computer program using FORTRAN 77 language for the adjustment of the observation.

* To carry out a statistical test to ascertain the reliability of the result obtained.

\section{Area of Study}

The area of study is situated in Federal Polytechnic Mubi (Mubi Campus) between longitude $13^{\circ} 05 \mathrm{E}$ and $13^{\circ} 15 \mathrm{E}$ and latitude $10^{\circ} 05 \mathrm{~N}$ and $10^{\circ} 15 \mathrm{~N}$ See fig 1.
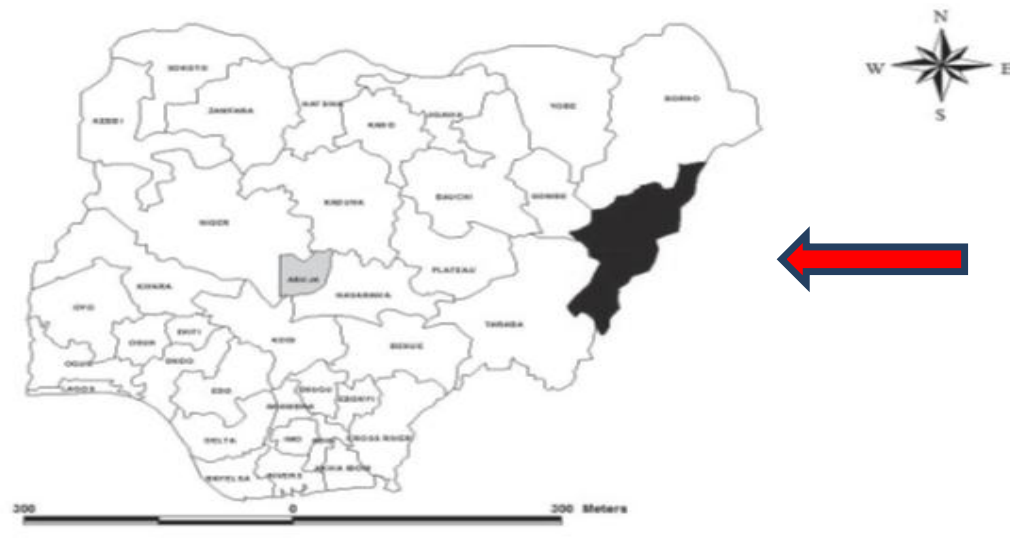

\section{LEGEND}

Abuja

Adamawa State

Mubi L.G.A

\section{Fig.1 Map of Nigeria Showing Adamawa State}

\subsection{Determination of EDM Zero Correction}

\section{Methodology and Field operations}

The procedure used to determine the zero correction of an EDM, was to take a straight long line and divide it into sections. Theses sections were measured and the long line was also measured and the zero correction determined. A distance of $500 \mathrm{~m}$ on a fairly flat ground was used on the site of the Project. The distance was subdivided into three and measurement was carried out in order to determine the EDM correction.

\begin{tabular}{llllll}
\hline 154.250 & & 161.816 & & 183.890 & \\
\hline $\mathrm{A}$ & $\mathrm{B}$ & & $\mathrm{C}$ & $\mathrm{D}$ \\
\hline
\end{tabular}




$\begin{array}{rlr}\mathrm{AB} & = & 154.250 \\ \mathrm{BC} & = & 161.861 \\ \mathrm{CD} & = & 183.890 \\ \mathrm{AD} & = & 500 \mathrm{~m} \\ & & \\ & C=\frac{D-(d)}{n-1}\end{array}$

Where $\mathrm{C}=$ the correction to the measured length

$\mathrm{D}=$ the overall measured length

(d) $=$ The sum of the measured bay length

$\mathrm{n}=$ the number of bay

$C=\frac{500-500.001}{3-1}=-0.0005 m$

\subsection{Setting Out of Baseline}

A wild $\mathrm{T}_{2}$ theodolite and ranging poles were used to set out the baseline. The theodolite was set up on the starting point after a pillar has been placed. The direction was defined by pointing the theodolite in the predetermined direction. Beacons were placed at the two ends of the baselines. The EDM used (wild distomat D1 1600) work in conjunction with theodolite and the battery fixed. It was then set over pillar MD101BL and leveled the reflector too. After that, the following operation was carried out. The height of EDM instrument and reflector's height were measured with line tape and recorded in the field book. The intension was to determine the slope correction to bring the measured slope distance to horizontal distance.

The reflector was sighted and the center of the prism was bisected, then the vertical and horizontal movement of the theodolite was clamped. Checks for battery and signal were made by switching on the instruments on/off switch. The display sowed 0000, indicating that the instrument was ready for operation. Measurement was triggered by lightly touching "MEASURE" knob. The distance measurement was performed automatically within 5" (second), during this time, points were flashing at the digital display and finally the measured distance was displayed.

* The vertical angle reading was recorded from the theodolite for slope correction.

* The atmospheric temperature was also recorded.

Only one measurement is needed to define the distance, assuming there are no gross and systematic errors in the measurement but due to some variations beyond the control of the observer during the measurement. Redundant measurements were made in order to evaluate standard errors and establish probabilities. These redundant measurements were used to detect mistakes in the field work and to find an estimate for a true value by the principles of least squares.

\subsection{EDM Measurement}

In this technique, distances were obtained by measuring the time taken for a pulse of laser radiation to travel from one instrument to a reflector and back. The distance D between instrument and reflector is given by:

$D=\frac{v t}{2}(\mathrm{iii})$

Where $\mathrm{t}$ is the measured transit time and $\mathrm{V}$ is the speed of propagation of electromagnetic radiation in the atmosphere. However, as the velocity of light (c) is equal to $299,792.5 \pm 0.4 \mathrm{~km} / \mathrm{s}$ (in vacuum), $\mathrm{t}$ is extremely small, [16].Therefore, the distance was determined by measuring the difference in phase angle between transmitted and reflected signals. This phase difference was usually expressed as a fraction of a circle which can be converted into distance when the frequency and the velocity are known.

\subsection{Meteorological Correction}

Effect to atmospheric conditions on wave velocity, uncertainty in the position of the electrical center of the transmitter, uncertainty in the effective center(s) of the reflector(s) and transmitters non linearity all contribute to the systematic error found in microwave instrument. The velocity, $\mathrm{v}$ of electromagnetic waves in air is a function of the speed of light in a vacuum $\mathrm{V}_{0}$ and the refractive index of air $\mathrm{n}$, yielding 
$v=\frac{v_{0}}{\eta}(\mathrm{iv})$

The constant $\mathrm{V}_{\mathrm{o}}$ is $299,792.5 \mathrm{~km} / \mathrm{s}$. The refractive indices of light

$$
n_{g}=1+\left(287.604+\frac{4.8864}{\lambda^{2}}-\frac{0.0648}{\lambda^{4}}\right) 10^{-6}
$$

Waves and microwaves in air are function of air temperature, atmospheric pressure and partial pressure of water vapor, which in turn depend on temperature and relative humidity. Since the EDM used (wild distomat $\mathrm{D}_{1} 1600$ ) is a light wave. It is necessary to calculate the refractive index $\left(\mathrm{n}_{\mathrm{g}}\right)$ of standard air given by the Barrell and Sears equation.

In which $\lambda$ is the wavelength of the carrier beam of light and the value of the $\lambda$ is 0.91 .

Owing to changes in temperature, pressure and humidity, the refractive index of air becomes $\eta_{\mathrm{a}}$ as given by

$$
n_{g}=1+\frac{0.359474\left(n_{g}-1\right)_{p}-1.5026 e\left(10^{-5}\right)}{273.2+t}
$$

Therefore, the humidity represented by water vapor pressure in the second term of above equation has little effects on light wave and usually can be ignored.

Where $\mathrm{p}=$ atmospheric pressure, $\mathrm{mmHg}$

$\mathrm{t}=$ air temperature, ${ }^{\circ} \mathrm{C}$

$\mathrm{e}=$ vapor pressure, $\mathrm{mmHg}$

Hence, the refractive index of air at each instruments setting was calculated,

$\mathrm{t}_{1} \mathrm{p}_{1 \mathrm{e}}$

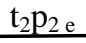

Where $\left(\eta_{1}\right)_{\mathrm{p}}=$ atmospheric pressure, $\operatorname{mmHg}\left(\eta_{2}\right)$

$\mathrm{t}=$ atmospheric temperature ${ }^{\circ} \mathrm{C}$

$\mathrm{e}=$ vapor pressure, $\mathrm{mmHg}$

The refractive index at the two ends of the lines was used to calculate the first velocity correction $(\Delta \mathrm{d})$.

\subsection{Slope Correction}

When the slope distance L has been obtained from an EDM measurement, a slope correction must be applied to it in order to obtain the equivalent horizontal distance.

$$
D=L \cos \theta=L \sin Z
$$

Where $\theta$ is the vertical angle

$\mathrm{Z}$ is the Zenith angle

Before calculating the horizontal distance some adjustment has to be made for the slope distance in order to obtained horizontal length of the line the procedure are as follows:

$$
\begin{aligned}
& \text { Slope distance }=1184.789 \mathrm{~m} \\
& \text { Instrument height } \quad=\quad 1.922 \mathrm{~m} \\
& \text { Reflector height }=1.65 \mathrm{~m} \\
& n=\frac{\text { Reflectance }- \text { Inst. Height }}{\text { Total Lenght }}
\end{aligned}
$$

Vertical angle $=89^{\circ} 07^{\prime} 33^{\prime \prime}\left(0^{\circ} 52^{\prime} 27^{\prime \prime}\right)$

Since the line of sight was inclined at an angle of $\left(1^{\circ} 13^{\prime} 43^{\prime}-0^{\circ} 00^{\prime} 47.35^{\prime}\right)$ to the horizontal length i.e. $1^{\circ} 14^{\prime} 30.35^{\prime}$ therefore, the reduced horizontal distance between the station is $1184.789 \operatorname{Cos} 1^{\circ} 14^{\prime} 30.35^{\prime \prime}=$ $1184.511 \mathrm{~m},[16]$. 


\section{Results and Discussion}

The data used in this work were obtained from measurement carried out on the baseline. Thirty different measurements were carried out on the baseline and the measurements were corrected for meteorological and geometrical effects. These are shown on the table below

\begin{tabular}{|l|l|l|l|l|l|l|l|l|}
\hline S/N & Observation & Correction & S/N & Observation & Correction & S/N & Observation & Correction \\
\hline 1 & 1184.789 & 1184.511 & 11 & 1184.812 & 1184.534 & 21 & 1184.821 & 1184.543 \\
2 & 1184.838 & 1184.56 & 12 & 1184.791 & 1184.513 & 22 & 1184.77 & 1184.492 \\
3 & 1184.817 & 1184.537 & 13 & 1184.806 & 1184.528 & 23 & 1184.801 & 1184.523 \\
4 & 1184.843 & 1184.565 & 14 & 1184.824 & 1184.546 & 24 & 1184.822 & 1184.544 \\
5 & 1184.778 & 1184.5 & 15 & 1184.802 & 1184.524 & 25 & 1184.836 & 1184.558 \\
6 & 1184.831 & 1184.553 & 16 & 1184.792 & 1184.514 & 26 & 1184.8 & 1184.522 \\
7 & 1184.824 & 1184.546 & 17 & 1184.807 & 1184.529 & 27 & 1184.812 & 1184.524 \\
8 & 1184.806 & 1184.528 & 18 & 1184.758 & 1184.48 & 28 & 1184.823 & 1184.545 \\
9 & 1184.83 & 1184.552 & 19 & 1184.803 & 1184.525 & 29 & 1184.824 & 1184.546 \\
10 & 1184.795 & 1184.517 & 20 & 1184.833 & 1184.555 & 30 & 1184.873 & 1184.595 \\
\hline
\end{tabular}

Table1: The observations and corrections

\subsection{Principles of Least Squares Adjustments}

The method of least squares adjustments was used to find the most probable value for the measured baseline. The method may be defined as a method which makes use of redundant observations in the mathematical modeling of a given problem with a view to minimizing the sum of squares of discrepancies between the observations and their most probable (adjusted) values subject to the prevailing mathematical model. The discrepancies between the observations and their most probable values are known as residuals [16].When redundant measurements are made, the number of discrepancies may occur between repeated measurements of the same quantity, since each measurement has a certain precision attached to it. Such discrepancies (residuals) have to be adjusted so as to obtain the most probable (adjusted) values of measured quantities. The role of adjustment is to derive values for residuals such that

$\mathrm{L}^{\mathrm{a}}=\mathrm{L}_{1}{ }^{\mathrm{b}}+\mathrm{V}_{1}=\mathrm{L}_{2}^{\mathrm{b}}+\mathrm{V}_{2}=\mathrm{L}_{3}^{\mathrm{b}}+\mathrm{V}_{3}=\quad$ (ix) is satisfied.

Where

$$
\mathrm{V}_{\mathrm{i}}=\mathrm{L}^{\mathrm{a}}-\mathrm{Li}^{\mathrm{b}}
$$

$\mathrm{Li}^{\mathrm{b}}=$ are the measured values of the quantity

$\mathrm{L}^{\mathrm{a}}$ is the adjusted value of $\mathrm{Li}^{\mathrm{b}}$ and is expected to be the closest to the true value.

$\mathrm{V}_{1}, \mathrm{~V}_{2}, \mathrm{~V}_{3}$, = residuals associated with the measured values.

Each estimate observation, $\hat{\imath}$ can be looked as a corrected observation, obtained from the measured value 1 , by adding a correction $\mathrm{v}$, to its i.e. equation (ix).

$$
\Phi=\mathrm{V}^{\mathrm{T}} \mathrm{P} \mathrm{V}
$$

Where

$\Phi=$ quadratic form of the sum of weighted squares of residuals.

$\mathrm{P}=$ weight matrix which may be full or diagonal matrix.

Weight matrix $(\mathrm{P})$ is full when observations are correlated and diagonal when observations are not correlated. Another process involves observations which are uncorrelated and of equal precision (weight). In this case $\mathrm{P}$ in equation (xi) becomes a scalar matrix. However, if $\mathrm{P}$ is unity, then least squares criterion simplifies to:

$$
\Phi=\mathrm{V}^{\mathrm{T}} \mathrm{P} \mathrm{V}
$$

The final steps of adjustment procedure consist of determination of the precision of various quantities computed from the adjustment, [9].

\subsection{Method of Observation Equation}

The method of observation equations is also known as method of parameters or variations of parameters. Observation equation may be defined as equations in which each adjusted observation is expressed 
as a function of some unknown adjusted parameters. Such a functional relationship will be valid only if the observations and the unknown parameters assume their "true" values (i.e. values without errors). Since in practice the true values of these quantities are not obtainable instead we make use of the most probable or adjusted observation and adjusted unknown parameters. The word "adjusted" is used to indicate that their calculated or observed values have been adjusted for the errors associated with them. The functional relationship between each adjusted observation and the adjusted parameters may represented mathematically a [2,9]

$L^{o}=F\left(X^{o}\right)$

Where: $X^{a}=X^{0}+x$

$\mathrm{X}^{\mathrm{O}}=$ approximate values of unknown parameters

$\mathrm{X}=$ correction to $\mathrm{x}^{\mathrm{o}}$

Equation (3.4) can be written as:

$L^{b}+V=F\left(X^{+x}\right)$

the nonlinear equations (xiii) may be linearized using Tailor's series expansion and the results, if the expansion is truncated at first order terms is:

$L^{b}+V=\left(\partial F \partial X^{a}\right)^{x}+F\left(X^{o}\right)$

Then we have, $\mathrm{V}=\mathrm{Ax}+\mathrm{L}$ (xiv)

Where: $\mathrm{A}=\partial F \backslash \partial X^{a}$ (matrix of differential, evaluated at $\mathrm{X}^{\mathrm{O}}$ )

$\mathrm{L}=\mathrm{F}\left(\mathrm{x}^{\mathrm{o}}\right)-\mathrm{L}^{\mathrm{b}}$

Substitute equation (xiv) into equation (xi) gives: $\Phi=(A x+L)^{T} P(A x+L)$

Equation $Ә \Phi \ \supset x$ to zero:

$\left(A^{T} P A\right) x+A^{T} P L=0$

$x=-\left(A^{T} P A\right)^{-1} A^{T} P L$

\subsection{Presentation and analysis of result}

The results were tested statistically to determine whether the result and the procedure used can be relied upon. That is, $\mathrm{V}^{\mathrm{T}} \mathrm{PV}$ is statistically tested to see whether it falls within the specified confidence limit or not, [2]. This is done by means of a chi square $\left(\mathrm{X}^{2}\right)$ test. That is testing the hypothesis.

Null hypothesis $\mathrm{H}_{\mathrm{o}}: \mathrm{V}^{\mathrm{T}} \mathrm{PV} \delta^{2}{ }_{\mathrm{o}}\left(\mathrm{V}^{\mathrm{T}} \mathrm{PV}\right.$ is within the confidence limit)

Alternative hypothesis $\mathrm{H}_{1}: \mathrm{V}^{\mathrm{T}} \mathrm{PV} \neq \delta^{2}{ }_{0}\left(\mathrm{~V}^{\mathrm{T}} \mathrm{PV}\right.$ is outside the confidence limit).

Where $\mathrm{V}^{\mathrm{T}} \mathrm{PV} / \delta^{2}{ }_{\mathrm{o}}$, is the computed statistics $\left(\mathrm{X}^{2}\right)$.

This is a two tailed test where the Alternative Hypothesis $\left(\mathrm{H}_{1}\right)$ is rejected if the computed statistics is outside the confidence limit. The confidence limits are the upper limit and the lower limit of the statistics table. They are obtained in the statistics table as $x_{1-a / 2, \text { df }}^{2}$ for upper limit and $x^{2}$ a/2,df for lower limit, where $\alpha$ is the level of significance while $\mathrm{df}$ is the degree of freedom.

\section{Presentation of Result}

The result of the adjusted baseline was computed and found to be 1184.54027 , the computed statistics $\left(\mathrm{V}^{\mathrm{T}} \mathrm{PV}\right)$ was also found to be 0.01554 , at 0.05 level of significance $(\alpha)$, degree of freedom 29 , the following was obtained.

Upper limit $\left(x^{2}{ }_{1-\text { a/2,df }}\right)=5.02$

Lower limit $\left(x_{\mathrm{a} / 2, \mathrm{df}}^{1-}\right)=0.0098$ 


\subsection{Analysis of Result}

Here the $\left(\mathrm{V}^{\mathrm{T}} \mathrm{PV}\right)$ was found to be 0.01554 . At 0.05 level of significance $(\alpha)$, degree of freedom is 1 , we conclude that, since the computed statistics is within the confidence limit it is therefore drawn that the procedure used has not introduce distortion in the predicted values.

Analysis of the result obtained was done using statistical method. In the method, it was tested whether the result and the procedure used can be relied upon. That is, $\mathrm{V}^{\mathrm{T}} \mathrm{PV}$ is statistically tested to see whether it falls within the specified confidence limit or not, [2]. This is done by means of a chi square $\left(\mathrm{X}^{2}\right)$ test. That is testing the hypothesis.

Null hypothesis $\mathrm{H}_{\mathrm{o}}: \mathrm{V}^{\mathrm{T}} \mathrm{PV} \delta^{2}{ }_{\mathrm{o}}\left(\mathrm{V}^{\mathrm{T}} \mathrm{PV}\right.$ is within the confidence limit)

Alternative hypothesis $\mathrm{H}_{1}: \mathrm{V}^{\mathrm{T}} \mathrm{PV} \neq \delta^{2}{ }_{0}\left(\mathrm{~V}^{\mathrm{T}} \mathrm{PV}\right.$ is outside the confidence limit).

Where, $\mathrm{V}^{\mathrm{T}} \mathrm{PV} / \delta^{2}{ }_{\mathrm{o}}$ is the computed statistics $\left(\mathrm{X}^{2}\right)$.

This is a two tailed test where the Alternative Hypothesis $\left(\mathrm{H}_{1}\right)$ is rejected if the computed statistics is outside the confidence limit. The confidence limits are the upper limit and the lower limit of the statistics table. They are obtained in the statistics table as $x_{1-a / 2, \mathrm{df}}^{2}$ for upper limit and $x^{2}$ a/2,df for lower limit, where $\alpha$ is the level of significance while $\mathrm{df}$ is the degree of freedom.

\section{Conclusion}

In this work, observations were made on a baseline in other to determine its correct distance. Thirty different observations were carried out and meteorological and slope corrections were applied. A least squares method of correcting observations based on the observation equation method was used to correct the measurement. The adjusted length of the baseline was found to be 1184.54027. This was achieved through least squares adjustment using a computer program written in FORTRAN 77 language. The computed statistics was found as 0.01554 which fall within the confidence limit. It was revealed that the result obtained can reliably be used for further studies. It can therefore be drawn that, a baseline was successfully measured and the result so obtained can reliably be used.

\section{Recommendations}

The process of least squares adjustment using observation equation method has been found appropriate base on the result obtained in the adjustment of measurement carried out by an EDM for the establishment of a baseline. It can therefore be adopted in other studies or works that involved measurement of baseline. In carrying out triangulation, trilateration, traversing etc in that area for instance, the measured baseline so obtained can be of great importance. This is because the baseline can be used as initial baseline for the work. The established beacons if coordinated can serve as good controls for other survey work.

\section{References}

[1] Allan, A. L., Hollwey J. R., Maynes J. H. B. (1968): Practical Field Survey and Computation William Heinemann Ltd. London, First Edition

[2] Ayeni O. O. (2001): Statistical Adjustment and Analysis of Data Lecture notes series.Department of Surveying and Geoinformatics, University of Lagos

[3] Bakari Z. (2001): Establishment and Calibration of Baseline Using EDM, (Unpublished) First Degree Project of the Federal University of Technology, Yola, Adamawa State, Nigeria.

[4] Bannister, A. and Raymond, S. October (1991): Surveying, Unabridged editions of British Publishers $6^{\text {th }}$ edition.

[5] Bomford, G. (1980): Geodesy, Oxford University Press Inc, New York. $4^{\text {th }}$ edition.

[6] Bornes, W. M. (1988): Basic Surveying Batter Worth \& Co. (Publishers) Ltd.

[7] Commonwealth of Austraila, 1960

[8] Featherstone W. E., Forward T. A., Penna N. T., Stewart M. P., Sakiri M. (2001): Department of Spatial Sciences, Curtin University of Technology, Bentley, Western Australia

[9] Idowu T. O. (1987): Traverse Network Adjustment by Condition Equations and Observation Equations Methods of Least Squares A Comparison. First Degree Project of University of Lagos, Nigeria

[10] Maffit H. F. and Bouchard H. (1975): Surveying, Harper and Raw Publisher, New York.

[11] MC Carthy R., Houghton H. (2001): Establishment of a GNSS Testing and Validation Facility in Perth, Department of Land Administration, Midland, Western Australia.

[12] Raymond E., Davis, S. James M. and Edward M. (1981): Surveying:Theory,

[13] Schofield, W. (1984): Engineering Surveying 2, British Library Cataloguing (Publishers) $2^{\text {nd }}$ ed.

[14] Statistics S. Villy, K. (2003): Proceedings $11^{\text {th }}$ FIG Symposium on Deformation Measurements Stathis Stiros ${ }^{1}$, Aris Chasapis ${ }^{2}$ and Villy Kontogianni ${ }^{11}$ Lab of Geodesy, Department of Civil Eng. Patras University, Patras 26500, Greece.

[15] Surcon (2003): Specification for Large Scale Cadastral and Engineering Surveying in Nigeria. Surveyor Council of Nigeria (Publishers)

[16] Uren, J. and Price, W. F. (1981): Surveying for Engineers Macmillan Edition Ltd. London (Publishers) $3^{\text {rd }}$ ed.

[17] Keller, Wolfgang. (2004): Wavelets in geodesy and geodynamics / Wolfgang Keller. P. Includes bibliographical references and index. ISBN 3-11-017546-0 Wavelets (Mathematics) 2 Geology _ Mathematics. I. Title. QE33.2.W38K45 